\title{
Fatigue Crack Growth in Bodies with Thermally Sprayed Coating
}

\author{
O. Kovář̀k, P. Haušild, J. Medřický, L. Tomek, J. Siegl, R. Mušálek, N. Curry, and S. Björklund
}

(Submitted May 22, 2015; in revised form September 14, 2015)

\begin{abstract}
Many applications of thermally sprayed coatings call for increased fatigue resistance of coated parts. Despite the intensive research in this area, the influence of coating on fatigue is still not completely understood. In this paper, the localization of crack initiation sites and the dynamics of crack propagation are studied. The resonance bending fatigue test was employed to test flat specimens with both sides coated. Hastelloy-X substrates coated with classical thermal barrier coating consisting of yttria stabilized zirconia and NiCoCrAIY layers. The strain distribution on the coating surface was evaluated by the Digital Image Correlation method through the whole duration of the fatigue test. Localization of crack initiation sites and the mode of crack propagation in the coated specimen are related to the observed resonance frequency. The individual phases of specimen degradation, i.e., the changes of material properties, crack initiation, and crack propagation, were identified. The tested coatings strongly influenced the first two phases, and the influence on the crack propagation was less significant. In general, the presented crack detection method can be used as a sensitive nondestructive testing method well suited for coated parts.
\end{abstract}

Keywords Thermal barrier coating, Fatigue, Crack growth, Digital image correlation, Failure mechanism

\section{Introduction}

Thermally sprayed coatings are often used to protect critical components from wear, temperature, or aggressive environment. For many of these components, coating or underlying substrate failure may have serious consequences. Therefore, the fatigue resistance of the coatingsubstrate composite subjected to cyclic mechanical loading is an important engineering parameter.

During the last few decades, significant research effort has been focused on finding fundamental factors that influence the fatigue life of coated components. The effects of residual stresses (Ref 1-6), interface properties

This article is an invited paper selected from presentations at the 2015 International Thermal Spray Conference, held May 11-14, 2015, in Long Beach, California, USA, and has been expanded from the original presentation.

O. Kovář́ík, P. Haušild, L. Tomek, and J. Siegl, Faculty of Nuclear Sciences and Physical Engineering, Czech Technical University in Prague, Trojanova 13, 12000 Praha 2, Czech Republic; J. Medřický, Faculty of Nuclear Sciences and Physical Engineering, Czech Technical University in Prague, Trojanova 13, 12000 Praha 2, Czech Republic and Institute of Plasma Physics CAS, v.v.i, Za Slovankou 1782/3, 18200 Praha 8 , Czech Republic; R. Mušálek, Institute of Plasma Physics CAS, v.v.i, Za Slovankou 1782/3, 18200 Praha 8, Czech Republic; and N. Curry and S. Björklund, Production Technology West, University West, 46186 Trollhättan, Sweden. Contact e-mail: ondrej.kovarik@fjfi.cvut.cz.
(Ref 7,8), or failure mode of the coatings (Ref 9-11) were investigated. Despite the number of articles published, the actual damage scenario of many types of coating-substrate composites is still not fully understood. The fractographic analysis generally does not provide clear indications of crack initiation and propagation in the coating. The question arises whether the crack initiates in the coating and propagates toward the substrate, or the coating damage is a consequence of substrate crack opening. For some coatings, this question can be answered by observing the cracks on sample cross section (Ref 6, 12, 13). For most of the other cases, the complicated coating micromorphology calls for the use of different method.

Three main types of degradation processes take place during the fatigue life of coated bodies, i.e., changes of material properties, fatigue crack initiation, and fatigue crack growth. The changes of material properties can be either permanent or temporary and usually, but not necessarily, show saturation behavior (Ref 14). The fatigue cracks may initiate at specific locations in the substrate and coating, or at the coating-substrate interface. The fatigue crack growth can proceed in both coating and substrate materials, with different damage sequences possible. The specimen resonance frequency inherently reflects the immediate specimen stiffness and therefore is a very sensitive indicator of the fatigue damage (Ref 11). However, further information is necessary to separate the influence of the individual types of degradation processes. The most important task is the identification of the moment of crack initiation and the description of the following crack growth. However, the processes described above generally overlap in the time domain, which makes their identification rather complex.

The resonance bending $(R=-1)$ fatigue test of flat unnotched specimens is an efficient way for testing fatigue 
properties of coated materials (see e.g., Ref 6, 9, 11, 15, 16). The fatigue test device "SF-Test" developed at Czech Technical University is capable of high loading frequency $(\sim 100 \mathrm{~Hz})$ and excites the specimen exactly at its first resonance mode. The fatigue test is therefore very fast and, at the same time, the loading frequency can be used to indicate stiffness changes of the coating-substrate composite with remarkable sensitivity and without the need of test interruption.

A direct observation of the coating surface can in principle provide relevant information regarding crack initiation and crack growth. Unfortunately, the complex coating surface morphology makes the direct crack observation a tedious task, especially, if the size and location of the crack is a priori unknown. In order to overcome these difficulties, a combination of direct optical surface monitoring and digital image correlation (DIC)based strain mapping system was developed. The strain mapping method enables unambiguous identification of strain concentration areas and also detection of crack mouths at the sample surface. The strain mapping based on DIC was already utilized by several authors to describe the strain field around cracks. The DIC methods that do not address the crack discontinuity directly (Ref 17-19) can be characterized as continuous DIC methods. In these methods, the crack is detected by thresholding the deformation field. On the other hand, discontinuous methods such as the subset 'splitting' (Ref 20) already presume the fatigue crack discontinuity and can be used as advanced crack detectors. Unfortunately, the computational cost of the discontinuous method is often very high.

In this study, we attempted to address the problems described in the above paragraphs, i.e., to locate the fatigue crack initiation sites and to describe crack propagation during fatigue experiment. Samples prepared at subsequent phases of thermal barrier coating (TBC) manufacturing process were used for the study. The research is closely related to the fatigue study of TBCs (Ref 21); however, the sample set presented in this study is reduced to single loading amplitude. The continuous DIC method based on surface strain thresholding is used for the crack detection.

\section{Materials and Methods}

The conventional TBC coatings were deposited by atmospheric plasma spray (APS) on Hastelloy-X substrates at University West, Trollhattan, Sweden. Sets P,
GB, APSBC, and APSBCTC correspond to subsequent stages of the coating process and are described in Table 1. The grit blasting was performed with alumina grit (53$63 \mu \mathrm{m})$ using the grit blasting mode of the M3 high-velocity air fuel (HVAF) torch (Uniquecoat Technologies, USA). For details concerning sample deposition and grit blasting parameters, substrate, and coating microstructures and phase composition, please refer to (Ref 21). The fatigue performance of samples tested in (Ref 21) at several loads is summarized in the form of a fatigue diagram in Fig. 1. The parameter of the fatigue plot is the strain range $\Delta \varepsilon_{y y}$ at the substrate surface in the middle of specimen fatigue lifetime. For the crack growth experiment presented in this study, a single strain range of $\Delta \varepsilon_{y y}=3.3 \times 10^{-3}$ was selected for simplicity. This choice ensures significant difference in the specimen fatigue lives and avoids runouts $(N>30 \times$ $\left.10^{6}\right)$ at the same time. The specimen surface in the critical region was observed throughout the fatigue test by the strain mapping method described below.

The fatigue testing was performed on the "SF-Test" resonance bending device for bending "fixed-free" flat cantilevers. The loading is performed at the first resonance frequency of the specimen, and the specimen loading is given by its first modal shape. The loading amplitude is controlled by maintaining the deflection amplitude $U$ of the specimen free end. The specimen geometry, region of crack initiation, axis naming convention, and the loading

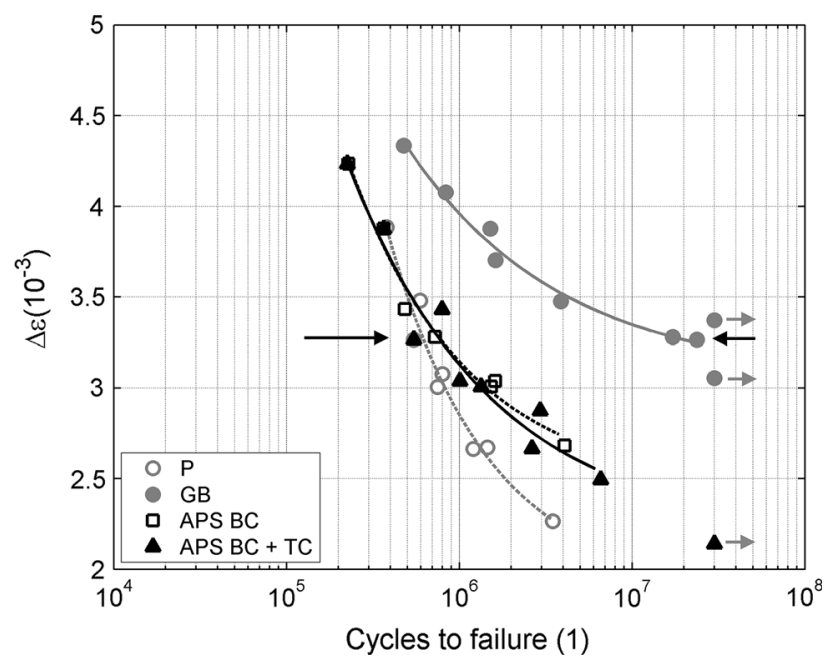

Fig. 1 Fatigue plot used for strain range selection. Black arrows show the selected strain range. Gray arrows show runouts

Table 1 List of tested samples, the corresponding fatigue lives $N$ and surface roughness $\boldsymbol{R}_{\text {a }}$

\begin{tabular}{|c|c|c|c|}
\hline Series (sample) & Treatment & $N$, cycles & $\boldsymbol{R}_{\mathbf{a}}, \mu \mathbf{m}$ \\
\hline $\mathrm{P}$ & As-received Hastelloy-X sheet, $H=4.8 \mathrm{~mm}$ & 544009 & $0.4 \pm 0.1$ \\
\hline GB & Grit blasted using HVAF gun & 17164135 & $2.4 \pm 0.1$ \\
\hline APSBC & $\begin{array}{l}\text { APS NiCoCrAlY bond coat on GB substrate, } h=225 \mu \mathrm{m} \text {, } \\
\text { Amperit } 827.873 \text { powder }\end{array}$ & 724581 & $12.2 \pm 0.6$ \\
\hline APSBCTC & APS BC + YSZ top coat, $h=225+250 \mu \mathrm{m}$ & 532612 & $11 \pm 0.6$ \\
\hline
\end{tabular}

$H$ and $h$ denote substrate and coating thickness 

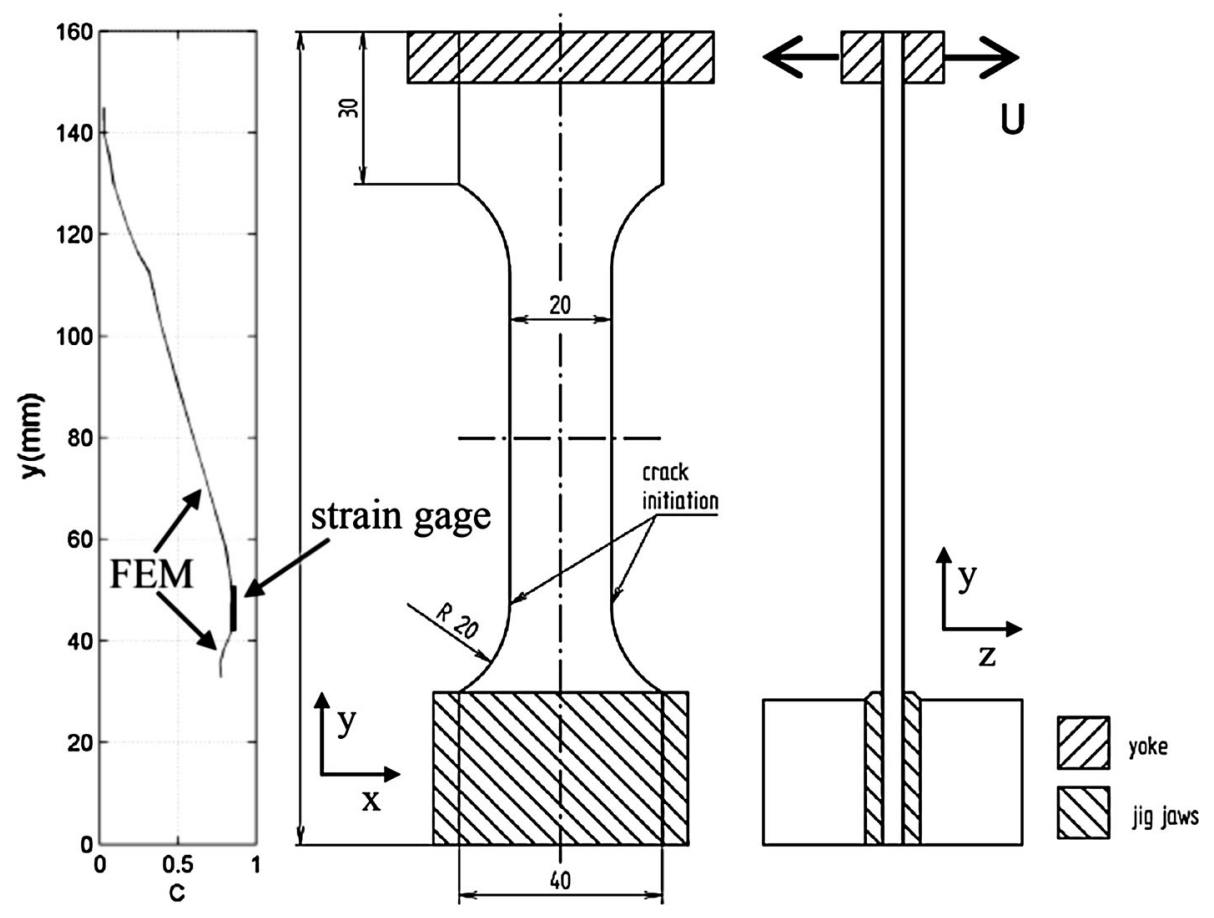

Fig. 2 Geometry of the specimen and the plot of loading factor $C(y)$ used to compute strain at arbitrary position $\Delta \varepsilon_{y y}\left(\left.U\right|_{N=0}, y\right) \cong 2 * C(y) * U^{*} H / 100 . H$ and $U$ denote the specimen thickness and deflection amplitude, respectively

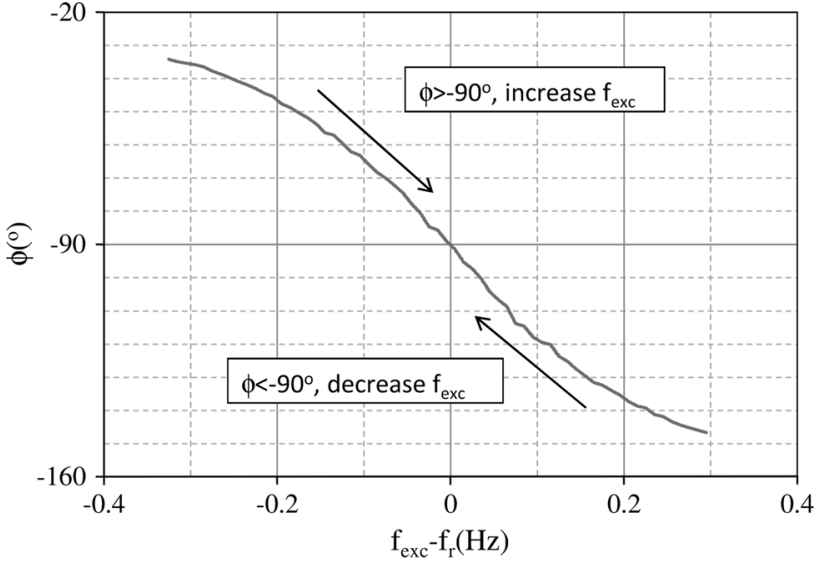

Fig. 3 The principle of phase shift technique used to maintain resonance. For the phase shift $\phi>-90^{\circ}$, the loading frequency is increased and vice versa

factor $C$ corresponding to the first modal shape are shown in Fig. 2. Due to the geometry of the sample and imposed bending, fatigue cracks initiate in the region of maximum straining close to fixed end. The strain range applied to substrate surface in this area was estimated by finite element modeling and verified successfully by strain gage measurement.

In contrast to other similar fatigue test machines (Ref 22, 23), the real-time phase shift technique is used to keep the loading frequency equivalent to the resonance frequency for the whole duration of the fatigue test. The phase shift technique updates the immediate loading frequency based on the measured phase shift between excitation and deflection according to Fig. 3. The shape of the $\phi(f)$ relation can be well approximated by the solution of forced damped single degree of freedom oscillator and used for the estimation of total loss factor $\eta$ of the sample. The phase shift and deflection amplitude are discriminated from the harmonic signals using the nonlinear method based on standard IEEE 1057. The described implementation of the phase shift technique maintains the phase shift to $0.5^{\circ}$ precision. The free end deflection amplitude $U$ is maintained with $\pm 5 \mu \mathrm{m}$ precision.

The typical course of sample resonance frequency $f$ and loss factor $\eta$ during a fatigue test is illustrated in Fig. 4 for sample coated with NiCoCrAlY bond coat. In the first part of fatigue life, before crack detection, both $f$ and $\eta$ decrease, i.e., simultaneous decrease of both specimen damping and specimen stiffness is observed. The underlying processes can be described as material property changes or microcrack formation. Both of these processes usually lead to saturation. In the second part of fatigue life, the frequency $f$ starts to gradually drop and the fatigue cracks are detected by DIC. At the same time, the damping increases due to energy dissipation in the plastic zone at the crack tip and due to the friction of crack faces. The source of crack damping is investigated in detail in (Ref 24).

The experiment stopping condition is formulated to be sensitive to the fatigue crack growth in final stage of the fatigue life. At the same time, the effects of material property changes and microcrack formation should be suppressed. It was observed that resonance frequency usually stabilizes approximately in the middle of specimen fatigue lifetime (see Ref 11), indicating the saturation of 


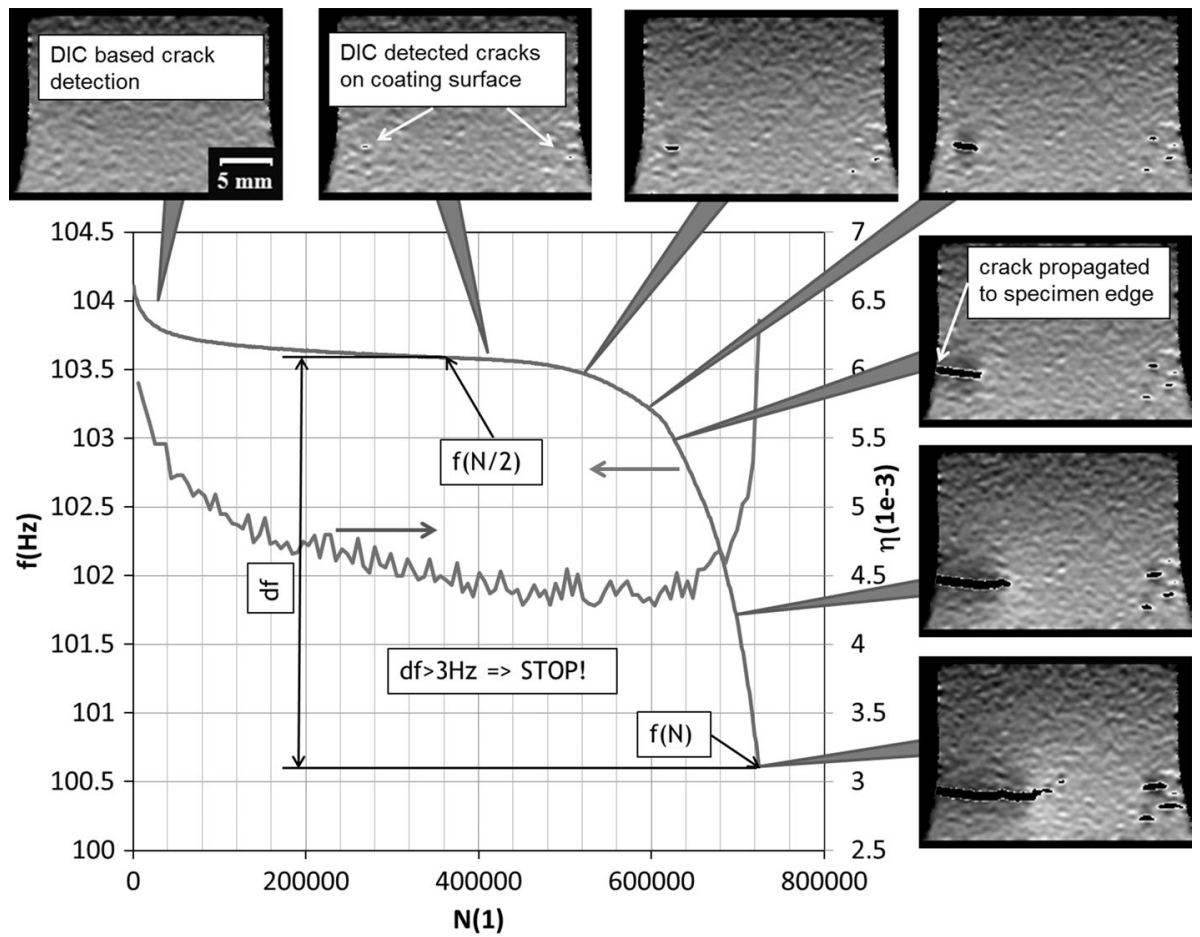

Fig. 4 The typical course of resonance frequency $f(N)$ and loss factor $\eta(N)$ during the fatigue and corresponding crack development

sample stiffness changes resulting from material property changes and formation of microcracks. Therefore, the value of sample resonance at specimen half-life $f(N / 2)$ can be used as a reference value. The stopping condition is then based on frequency drop $d f=f(N / 2)-f(N)$, where $f(N)$ is the actual loading frequency. The experiment is stopped, when $d f$ reaches an arbitrary value.

One peculiarity of the method comes from the fact, that the controlled variable is the deflection amplitude $U$ of the cantilever free end. The actual strain in the critical section (corresponding to the area $y=30-50 \mathrm{~mm}$ in Fig. 2) may change during the fatigue life due to localized material property changes such as cyclic hardening or softening or microcracks formation. For many materials, however, only minor changes are observed and the test can be regarded as strain controlled until the crack propagation takes place.

The strain mapping and crack detection were performed on images of the specimen surface captured at certain phase of the loading cycle, i.e., the image acquisition was synchronized to the moment, when the sample free end deflection reached its extreme position (see Fig. 5). At this moment, the observed specimen surface was at the maximum tensile strain, and crack opening was maximized. The images of the strained specimen surface were automatically obtained at fixed interval, corresponding approximately to $1 \%$ of expected specimen lifetime. Moreover, the surface images were also made at each $0.1 \mathrm{~Hz}$ of resonance frequency change to reflect the rapid changes in the specimen stiffness that take place at the beginning and at the end of the test.

In order to detect the localized surface deformation caused by the fatigue crack, the deformation field on the

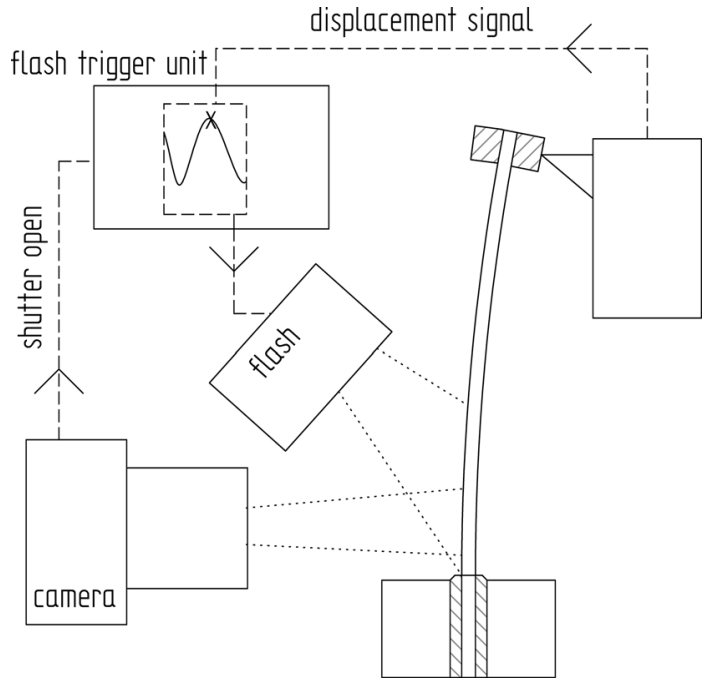

Fig. 5 The schematic drawing of image acquisition setup

sample surface was estimated by the digital image correlation method (DIC). The Ncorr software (Ref 25) was used to perform DIC computations and to evaluate the strain components $\varepsilon_{y y}, \varepsilon_{x x}$, and $\gamma_{x y}$. The subset radius of 20 pixels and subset spacing of 3 pixels were used. Unfortunately, the position of the observed area with respect to the camera is different in reference (unloaded) and current (deflected) state (see Fig. 5) of the specimen. Therefore, the specimen surface position in deflected state has to be known in order to correct the strain field. The approximate surface deflection curve computed by finite 


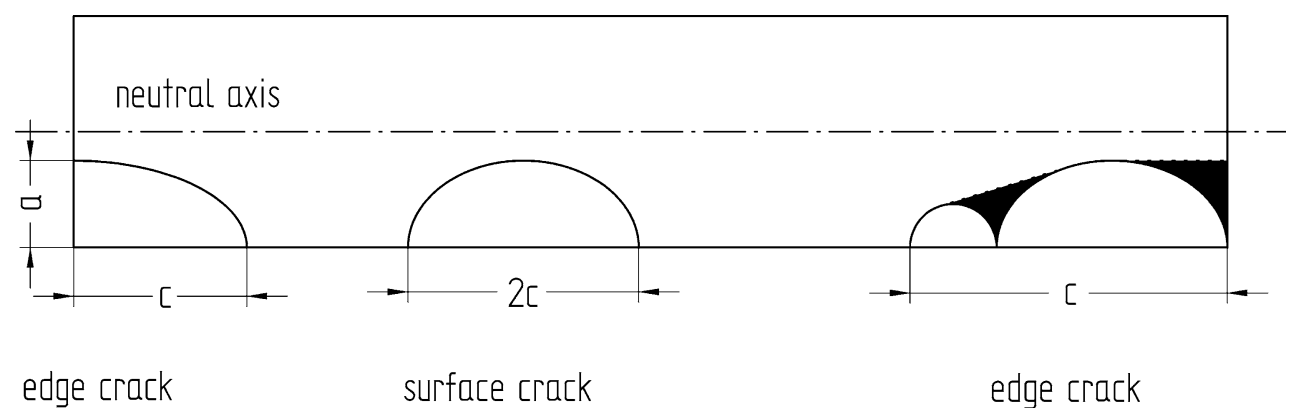

Fig. 6 The schematic drawing of crack description. The black areas are neglected in the used description

element method can be used for this purpose. However, even the uncorrected strain maps referenced to specimen at deformed configuration at the beginning of the test (see Fig. 4) offer valuable information on the strain distribution on the sample surface.

The corrected strain field was used for crack detection. The standard DIC protocol neglecting crack-induced strain discontinuities was used (Ref 25). The crack opening was detected as excessively large $\varepsilon_{y y}$ strain. For this threshold, a value of $7 \times 10^{-3}$ was selected. Selecting a different value in the range from $5 \times 10^{-3}$ to $10 \times 10^{-3}$ will have only minor influence on the obtained results. The individual crack mouths were identified automatically at the thresholded binary images, and corresponding crack growth curves were estimated by an in-house developed routine written in Matlab (MathWorks, USA).

Two types of cracks were detected by the DIC method: surface cracks and edge cracks (see Fig. 6). For simplicity, we describe the cracks as half ellipses in the case of surface cracks and quarter ellipses in the case of edge cracks. In bending load, the longitudinal stress decreases toward the neutral axis. As a consequence, the minor axis of the ellipse is perpendicular to the specimen surface and major axis is parallel to it. For the surface crack, the length of the crack mouth is equal to $2 c$, whereas for the edge crack, it is equal to $c$. The crack length is denoted $a$, and can be estimated by a suitable model from crack mouth length $c$. A crack mouth reaching the specimen edge is always considered as an edge crack, similarly, two cracks with common crack mouth are considered as one crack. This simplification deliberately neglects the remaining material denoted by black color areas in Fig. 6. However, the fatigue crack will quickly propagate through this remaining material due to the stress concentration. Therefore, the used simplification should not introduce significant discrepancy between the physical reality and the used description.

The experimental setup used (see Fig. 5) enabled the observation of only one side of the specimen during the fatigue test. However, due to the symmetry of the test, cracks can be expected also on the opposite side. Therefore, after the fatigue test, the specimens were rotated in the test device, and the cracks on the other side were detected from strain distribution recorded at reduced strain range $\Delta \varepsilon_{y y}=0.7 \times 10^{-3}$. In this case, the reduced $\varepsilon_{y y}$ threshold value of $1.5 \times 10^{-3}$ was used. The reduction of stress range is necessary, in order to prevent further crack growth during the crack detection.

To verify the findings of the DIC method, the fractographic analysis was performed after the fatigue test. The crack maps (see Fig. 8) were used to cut material containing major cracks out of the specimens. The cracks were opened by bending in the crack opening direction. In such a way, it is possible to open the fatigue cracks with limited plastic deformation of the sample and minimal damage of the fracture surfaces. The fractographic analysis and surface morphology observation were performed using the JEOL JSM-5510LV scanning electron microscope (SEM).

The surface roughness is an important engineering parameter influencing the fatigue endurance. Therefore, surface roughness was measured by a SURFTEST SJ-210 (Mitutoyo, Japan) portable roughness tester. The measurement was performed at speed of $v=0.5 \mathrm{~mm} / \mathrm{s}$ over a length of $l=2.5 \mathrm{~mm}$. Five longitudinal and five transversal measurements were evaluated for each sample. As the transversal and longitudinal roughness was not statistically different, the average values of all ten measurements are presented.

\section{Results}

The fatigue lives of the four examined specimens are summarized in Table 1. Clearly, the grit blasted (GB) specimen showed several orders of magnitude higher fatigue life than as-received and APS-coated samples. The results of the DIC method and fractographic analysis are summarized and discussed below in order to explain this difference.

The surface morphology of the specimens was favorable for the use of DIC method. The surface defects on asreceived sample $\mathrm{P}$, grit blasting imprints, and stuck grit on GB sample as well as splats of coated samples acted as a fine pattern that is necessary for the DIC method. The individual elements of the pattern were much smaller, than the subset diameter (see Fig. 7) and consequently were below the resolution limit of the DIC method. Apart from forming the fine pattern, the above-mentioned features also defined the surface roughness of the specimen (see Table 1). The grit blasting increased the $R_{\mathrm{a}}$ roughness only slightly, from 0.2 to $2.4 \mu \mathrm{m}$. The increased fatigue life of the GB specimen clearly shows that this increase of 

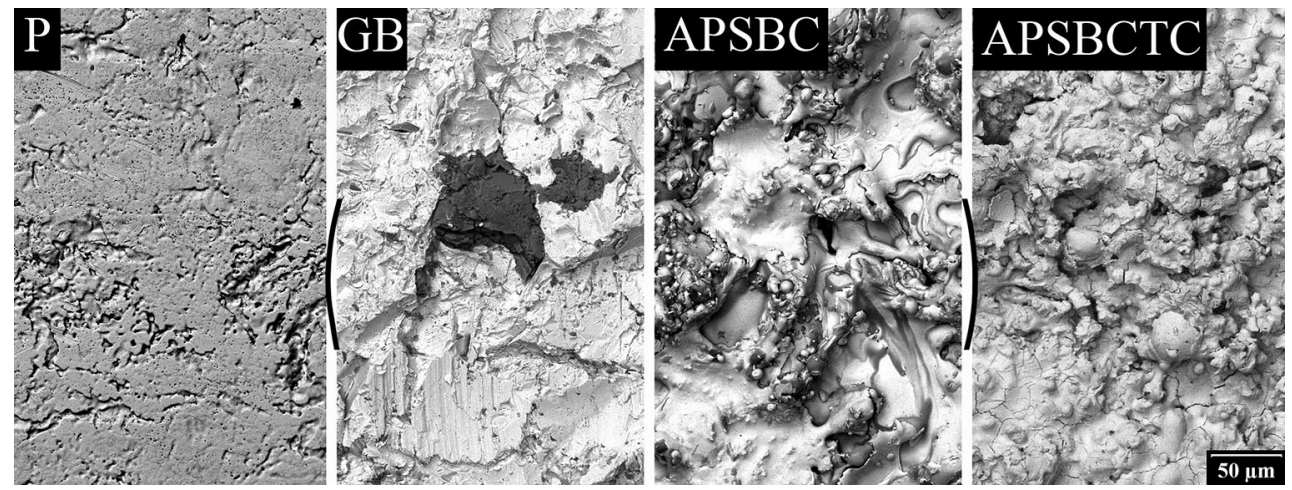

Fig. 7 SEM (backscattered electrons) micrograph of sample free surfaces. The brackets illustrate the diameter of the used circular DIC subset

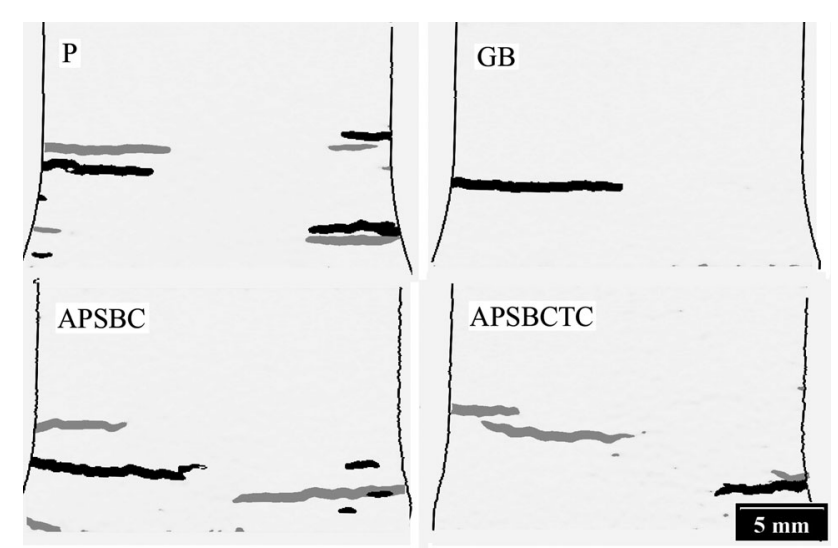

Fig. 8 The fatigue crack map of the specimens after the fatigue test. Cracks on observed side are black, cracks on the opposite side are gray

roughness was not able to counteract the other beneficial effects of grit blasting. More significant increase of $R_{\mathrm{a}}$ was measured for coated specimens, with $R_{\mathrm{a}}=12.2 \mu \mathrm{m}$, $R_{\mathrm{a}}=11.0 \mu \mathrm{m}$ for APSBC, and APSBCTC samples, respectively. The internal microstructure of the coating, however, contains defect such as voids and splats interfaces or cracks (see Ref 21). These internal defects may lead to more significant stress concentration, than the surface defects. Thus, further study is necessary to assess the effects of both coating roughness and internal defects on fatigue behavior.

The main results of the DIC method include the crack mouth positions detected on both surfaces of the four observed samples in Fig. 8, $\varepsilon_{y y}$ strain distribution at specimen half-life in Fig. 9, and crack growth curves in Fig. 10, 11, 12, and 13. These results provide important information on the specimen damage.

For the as-received $(\mathrm{P})$ specimen, the fatigue cracks on the observed surface had counterparts at similar location on the opposite surface of the specimen (see Fig. 8). Most probably, these paired cracks grew in parallel. The crack initiation is promoted by slightly inhomogeneous $\varepsilon_{y y}$ strain field (see Fig. 9). Multiple edge and surface cracks were detected on the observed sample side. The crack growth curves are not smooth, crack growth rate fluctuates significantly, and the crack mouth is not straight. This is a result of relatively coarse-grain microstructure of the specimen (Ref 21). The individual crack growth is also influenced by the stress redistribution caused by the growth of other cracks (see Fig. 10). For example, crack \#6 strain field is reduced by the growth of crack \#1, and therefore, crack \#6 gradually closes after approx. $420 \times 10^{3}$ fatigue cycles. Crack coalescence is also detected when edge crack \#5 joins the surface crack \#2.

In the GB specimen, only one edge fatigue crack was detected and its propagation is shown in Fig. 11. The fatigue crack growth curve is relatively smooth, and the crack mouth shape is straight. The most probable cause for this different behavior when compared to as-received sample is the significant deformation introduced to the substrate surface layer microstructure by grit blasting. This deformation leads to mechanical interlocking of grain boundaries, increasing the grain boundary density and subsequent strain hardening and residual stress buildup (Ref 6). Please note that combination of these beneficial effects overcame the detrimental effect of the presence of sharp grit residuals and higher roughness (Fig. 7) which may readily cause undesirable stress concentration at the surface and thus promote crack initiation. Another consequence of grit blasting is the relatively homogeneous strain field $\varepsilon_{y y}$ of the GB sample (see Fig. 9).

In the NiCoCrAlY bond coated specimen (APSBC) (see Fig. 12), edge and surface fatigue cracks were again detected on both sides of the specimen (Fig. 8). However, their location and size on the opposite sides of the specimen differed significantly. The fatigue crack growth was not smooth, and cracks coalescence took place. The most probable cause of both multiple initiation and irregular crack growth is the inhomogeneity of the coating caused by the interfaces of individual splats, often consisting of different phases. This inhomogeneity is reflected in the $\varepsilon_{y y}$ strain field depicted in Fig. 9.

Only one edge fatigue crack was detected on the observed side of sample with the composite YSZ+ NiCoCrAlY coating (APSBCTC) (see Fig. 13). On the opposite side, however, both surface and edge cracks were detected (see Fig. 8), and therefore, similar crack 

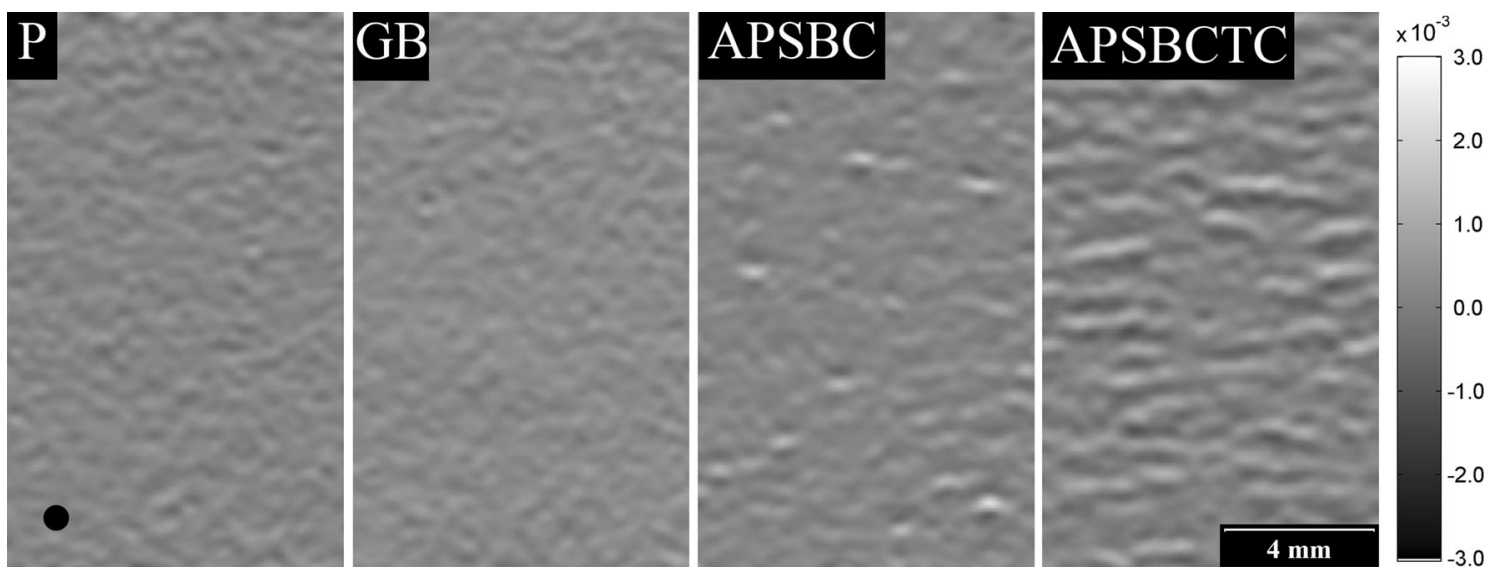

Fig. 9 Deformation map of specimen surface in the half of its fatigue lifetime. The size of DIC subset is marked by black disk

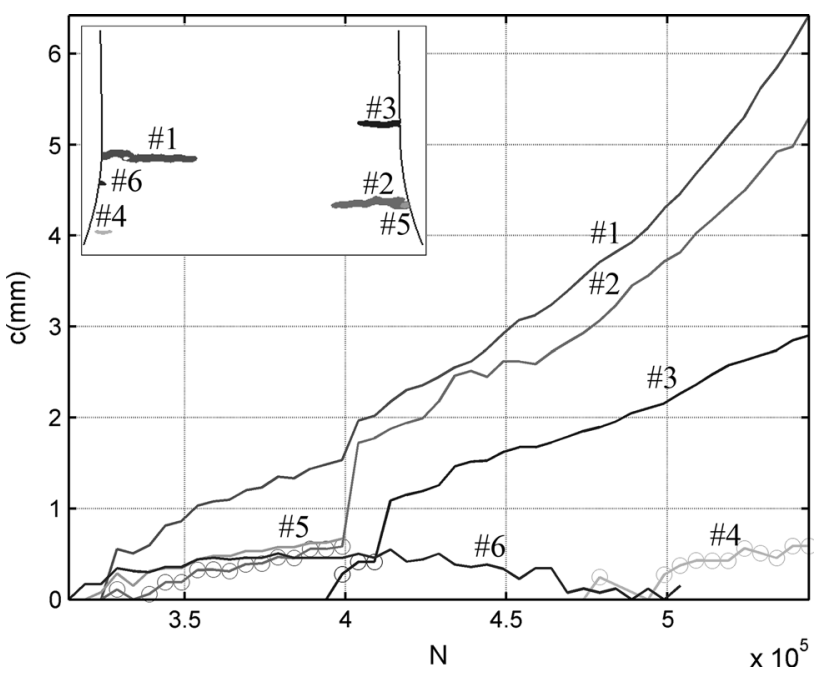

Fig. 10 As-received (P) sample — crack mouth shapes and crack growth curves, circles mark surface cracks

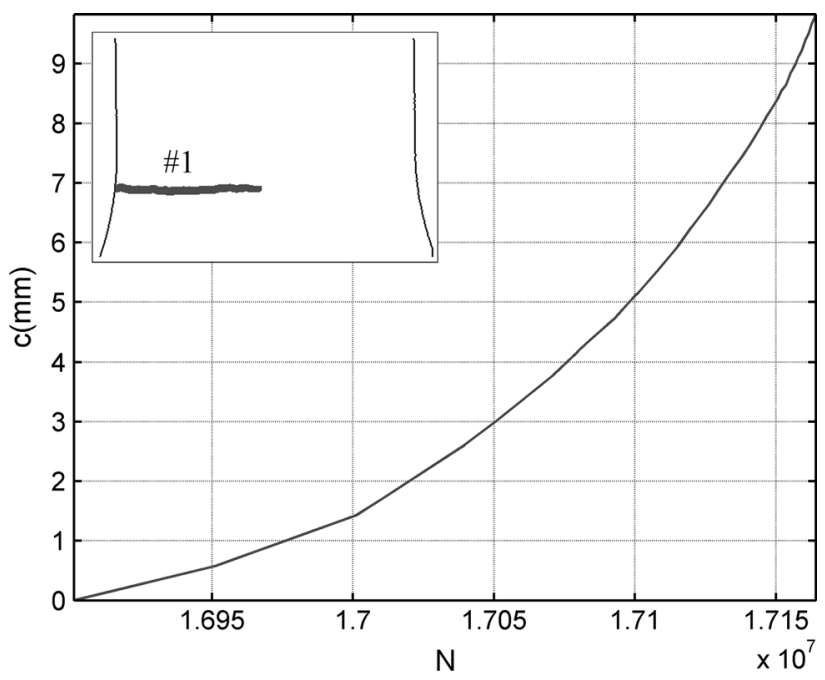

Fig. 11 Grit blasted (GB) sample—crack mouth shape and crack growth curve

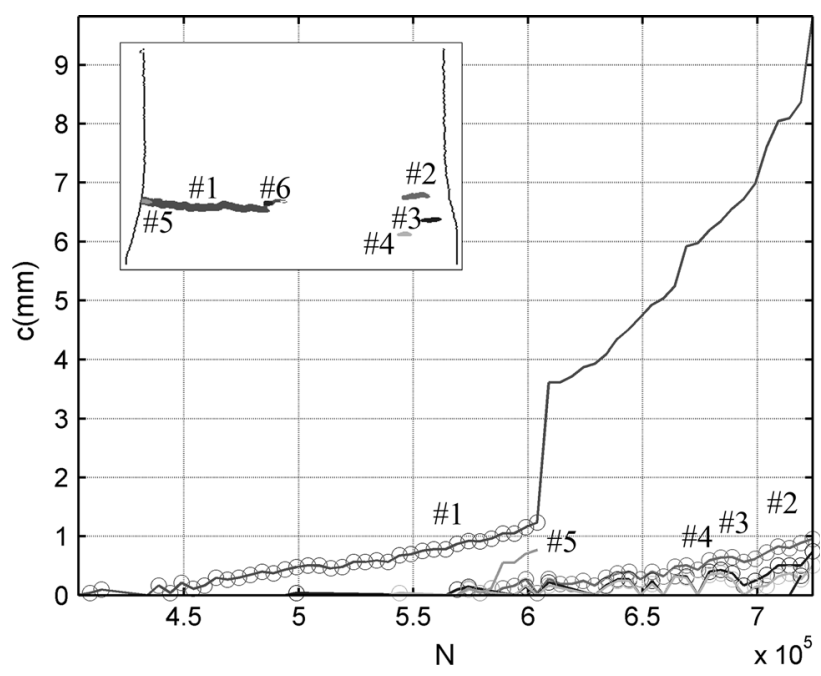

Fig. 12 NiCoCrAlY (APSBC) sample—crack mouth shapes and crack growth curves, circles mark surface cracks

initiation and propagation mode to the APSBC sample can be expected. The strain field at the specimen surface is even more inhomogeneous (see Fig. 9) than in the case of APSBC. The strain is localized in the ridges of length up to several millimeters, most probably corresponding to formation of the vertical segmentation cracks (Ref 26) or horizontal localized coating decohesion cracks observed in YSZ deposits e.g., in (Ref 27).

In order to compare the effect of surface treatment on fatigue crack growth kinetics, the crack growth curves of major edge cracks are summarized in Fig. 14. Despite the order of magnitude difference in the fatigue life of GB and other specimens, the crack growth rates are very similar. The only notable difference is the slightly slower crack growth rate of the $\mathrm{P}$ specimen. The pairing of the fatigue cracks on the opposite surface of the specimen (see Fig. 8) may be causing this slow down effect. Based on the data in Fig. 14, it can be stated that for the observed crack lengths, the surface treatment of the sample does not have significant influence on the crack growth stage. 
The results of the DIC method were compared with the results of the fractographic analysis carried out on fracture surface. The final crack mouth length $c$ and crack initiation site positions are compared in Table 2. The results of DIC

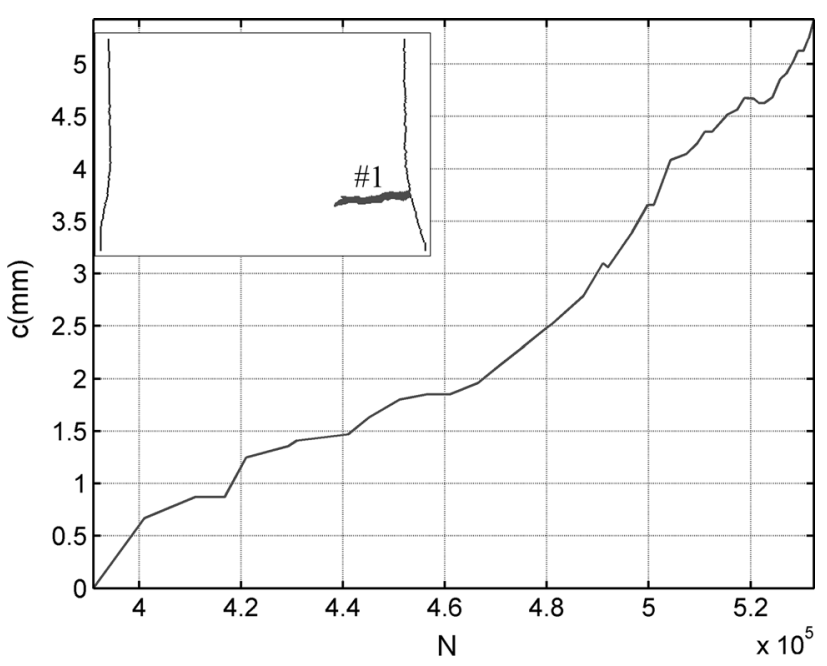

Fig. 13 YSZ top coat with NiCoCrAlY bond coat (APSBCTC) sample—crack mouth shape and crack growth curve

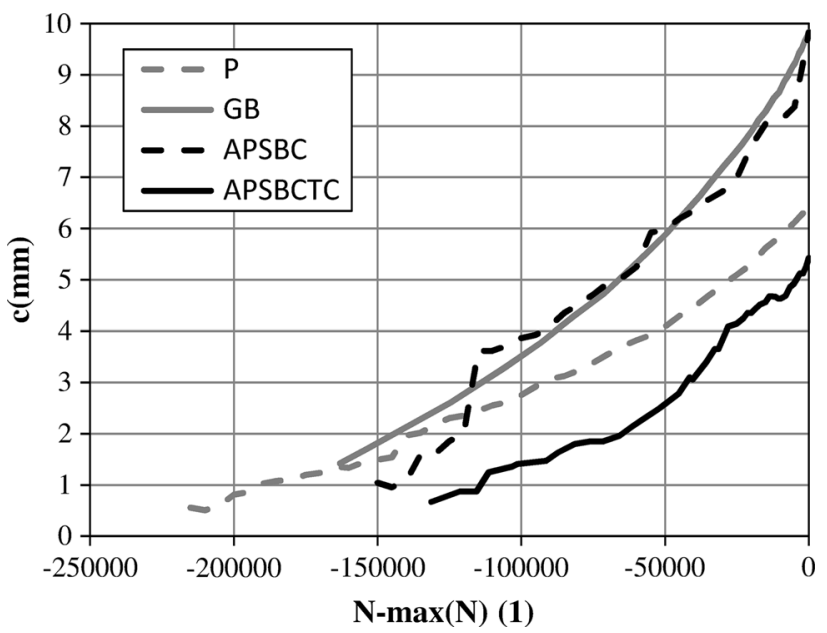

Fig. 14 Comparison of cracks growth curves $c(N-\max (N))$ of the largest edge crack of each specimen. Zero corresponds to the end of fatigue life and the fractographic analysis are very similar for the $\mathrm{P}$ and GB sample demonstrating applicability of the developed method for crack length measurement. For the APSBC sample, significantly longer crack was detected by DIC on the sample surface (coating) then by fractographic analysis in the substrate. This finding supports the hypothesis that the fatigue crack in the bond coat is forerunning the fatigue crack in substrate at least in the final stages of the fatigue life. The cracks in the coating probably opened to accommodate the deformation at crack tip strain concentration zone. The question to ask is, however, whether the cracks in the bond coat above the stress concentration zone are connected to the magistral crack, or whether DIC methods are simply unable to separate several small neighboring cracks due to its low resolution. For the APSBCTC coating, the difference between DIC and the fractographic analysis is considerably smaller. In this case, however, the observed crack was significantly shorter than in case of APSBC sample, and therefore, the strain concentration at the crack tip might be not strong enough to cause coating cracking. Alternative hypothesis is that the cracking of the bond coat was obscured by the top coat.

Apart from geometrical comparison with the DIC method, the fractographic analysis revealed significant morphological differences in crack initiation and propagation. The microfractographic features of the coating are extremely difficult to identify them due to the complicated coating microstructure (see Ref 6, 16, 28). All fatigue cracks propagated in a shape of a half or quarter ellipse with major axis situated at the substrate surface, justifying the approximation in Fig. 6. For the as-received P sample, the cracks initiated below sample surface at favorably oriented grain boundaries, probably in the vicinity of inherent precipitates. The early stages of crack growth were influenced by the material structure forming large facets (Fig. 15). In contrast to $\mathrm{P}$ specimen, the fatigue crack initiation of GBand APS-sprayed specimens was caused by the micro-notches induced by grit blasting. The transgranular facets can be found around the blasting particle imprints, but they are significantly smaller (see Fig. 16) than in the case of as-received $\mathrm{P}$ samples, probably as a result of the grit blasting that refined the subsurface microstructure. The microstructure deformation of the substrate surface forms the fatigue crack retardation zone, up to a depth of $160 \mu \mathrm{m}$ below the substrate surface. In this zone, the fatigue crack growth is slowed down considerably. The crack propagates

Table 2 Comparison of crack initiation sites location referenced to the specimen edge $x$ and crack lengths $c$ obtained using the DIC method and fractographic analysis

\begin{tabular}{|c|c|c|c|c|c|}
\hline Sample & Crack & $c_{\mathrm{DIC}}, \mathbf{m m}$ & $c_{\text {fracto, }}, \mathbf{m m}$ & $x_{\text {DIC }}, \mathbf{m m}$ & $x_{\text {fracto, }}, \mathrm{mm}$ \\
\hline \multirow[t]{2}{*}{$\mathrm{P}$} & \#1 & 6.41 & 6.45 & 0.27 & 0.35 \\
\hline & \#2 & 5.29 & 5.37 & 0.05 & 0.00 \\
\hline GB & \#1 & 9.83 & 9.75 & 0.05 & 0.00 \\
\hline \multirow{2}{*}{ APSBC } & $\# 1$ & 9.63 & 7.82 & 2.53 & $2.50 *$ \\
\hline & \#3 & 0.64 & 0.65 & 1.53 & 1.57 \\
\hline APSBCTC & \#1 & 5.32 & 5.26 & 0.41 & 0.47 \\
\hline
\end{tabular}




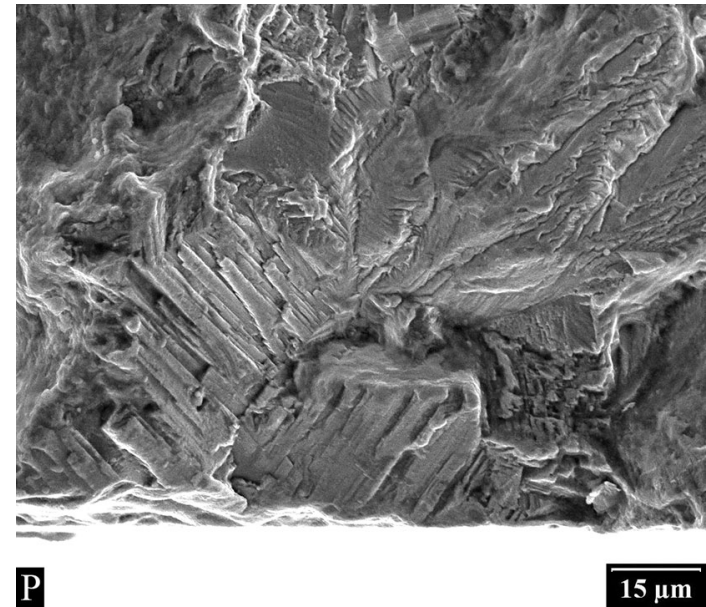

Fig. 15 Typical micromorphology of crack initiation sites of $\mathrm{P}$ specimens. Crack propagates from bottom to top of the image

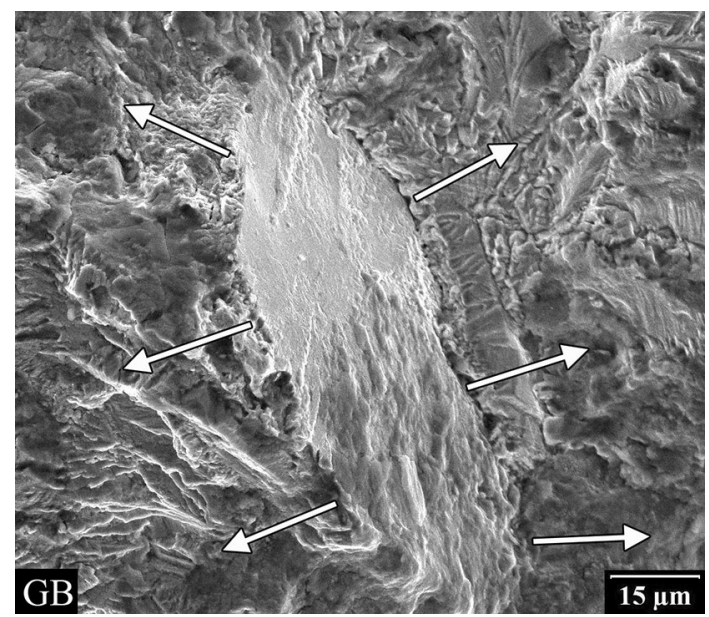

Fig. 16 Crack initiation site of GB specimen. Arrows show crack propagation from grit blasting particle imprint

from the zone boundary toward the interior of the substrate as well as to the substrate surface (see Fig. 17). This zone is preserved even after coating deposition in APSBC and APSBCTC specimens. The crack retardation can be characterized by compressive residual stress and microstructural changes such as strain hardening according to (Ref 6, 29). Compressive residual stress introduced by grit blasting can result in significant crack closure and related fracture surface obliteration, an effect clearly observed on the fracture surface of the crack retardation zone (see Fig. 17).

\section{Conclusions}

The obtained results show that the DIC method can be efficiently utilized for localization of crack initiation sites and estimation of crack growth curves in specimens subjected to resonance fatigue test. The results obtained

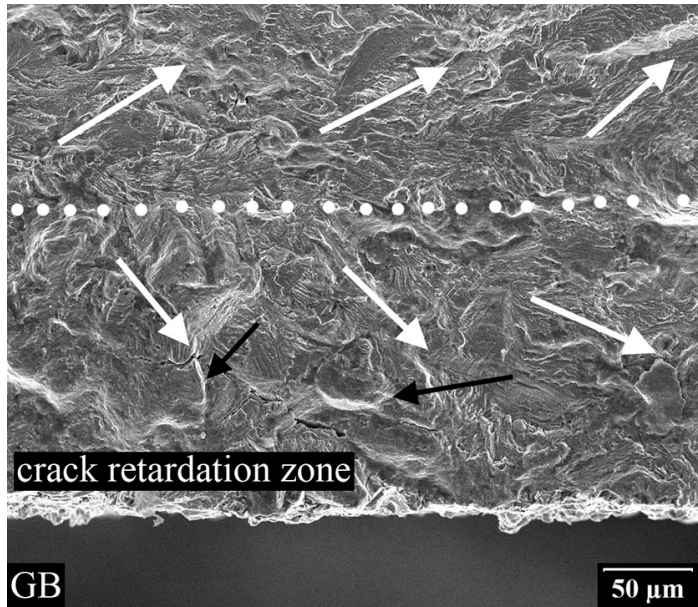

Fig. 17 The crack retardation zone introduced into substrate by grit blasting. Substrate surface is at the bottom of image. White arrows show fatigue crack propagation directions. Black arrows point to obliterated areas. The zone boundary is marked by white dots

for specimens corresponding to individual phases of TBC preparation fatigue tested at a strain range $\Delta \varepsilon_{y y}=3.3 \times 10^{-3}$ can be summarized as follows:

- Fatigue lives of the HVAF GB substrate GB are about 35 times longer than the fatigue lives of the asreceived $\mathrm{P}$ and coated specimens APSBC and APSBCTC.

- The localization, types of initiation (surface or edge), and total number of fatigue cracks in the particular specimen are related to its surface treatment.

- In the as-received P specimen, multiple surface and edge cracks initiated and major cracks propagated symmetrically on both surfaces of the specimen. Crack interactions caused by strain field redistribution were observed as well as crack coalescence.

- Only one edge crack was detected for the GB specimen.

- For the coated APSBC and APSBCTC specimens, multiple edge and surface cracks initiated, and the major crack symmetry observed on the $\mathrm{P}$ specimen was however not retained.

- Differences in the strain field character on the specimen surfaces were detected. The most homogeneous strain field was detected on the GB specimen. The increased strain field inhomogeneity was detected on the surface of the P, APSBC, and APSBCTC specimen.

- The crack retardation zone was introduced to the substrate by grit blasting and was retained even after the coating deposition. As this zone is present both in the GB and coated specimens, another factor explaining the fatigue life differences has to be found. The detected strain field inhomogeneities can be considered as such factor and can potentially explain the observed fatigue life differences. However, more detailed multiscale study of the strain field is necessary. 
- The estimated crack growth rates of all observed specimen are similar, the primary influence of the surface treatment is on the crack initiation and the very early stages of crack growth.

The DIC method can provide important information concerning the fatigue damage of the specimen even when the cracking induced strain field discontinuity was neglected by the DIC algorithm. At the same time, the method provides a sensitive robust nondestructive testing tool for crack detection. The inclusion of crack-induced strain discontinuity to the DIC algorithm would enable the crack opening displacement measurement and would also improve the sensitivity of crack detection. New type of such algorithm was already developed by the authors of this paper and is currently tested.

\section{Acknowledgement}

This study was supported by the Czech Science Foundation Grant project GAČR 14-36566G.

\section{References}

1. K. Padilla, A. Velasquez, J.A. Berrios, and E.S.P. Cabrera, Fatigue Behavior of a 4140 Steel Coated with a NiMoAl Deposit Applied by HVOF Thermal Spray, Surf. Coat. Technol., 2002, 150(2-3), p 151-162

2. H.J.C. Voorwald, R.C. Souza, W.L. Pigatin, and M.O.H. Cioffi, Evaluation of WC-17Co and WC-10Co-4Cr Thermal Spray Coatings by HVOF on the Fatigue and Corrosion Strength of AISI, 4340 Steel, Surf. Coat. Technol., 2005, 190(2-3), p 155-164

3. J.A.M. de Camargo, H.J. Cornelis, V.M.O.H. Cioffi, and M.Y.P. Costa, Coating Residual Stress Effects on Fatigue Performance of 7050-T7451 Aluminum Alloy, Surf. Coat. Technol., 2007, 201(24), p 9448-9455

4. H.J.C. Voorwald, R. Padilha, M.Y.P. Costa, W.L. Pigatin, and M.O.H. Cioffi, Effect of Electroless Nickel Interlayer on the Fatigue Strength of Chromium Electroplated AISI, 4340 Steel, Int. J. Fatigue, 2007, 29(4), p 695-704

5. R.C. Souza, H.J.C. Voorwald, and M.O.H. Cioffi, Fatigue Strength of HVOF Sprayed $\mathrm{Cr}(3) \mathrm{C}(2)-25 \mathrm{NiCr}$ and WC-10Ni on AISI, 4340 Steel, Surf. Coat. Technol., 2008, 203(3-4), p 191-198

6. O. Kovarik, P. Hausild, J. Siegl, Z. Pala, J. Matejicek, and V. Davydov, The Influence of Plasma Sprayed Multilayers of $\mathrm{Cr}_{2} \mathrm{O}_{3}$ and Ni10wt\%Al on Fatigue Resistance, Surf. Coat. Technol., 2014, 251, p 143-150

7. M.Y.P. Costa, M.L.R. Venditti, H.J.C. Voorwald, M.O.H. Cioffi, and T.G. Cruz, Effect of WC-10\%Co- $\%$ Cr Coating on the Ti6Al-4V Alloy Fatigue Strength, Mater. Sci. Eng. -Struct. Mater. Prop. Microstruct. Process., 2009, 507(1-2), p 29-36

8. E.S. Puchi-Cabrera, M.H. Staia, J. Lesage, D. Chicot, J.G. La Barbera-Sosa, and E.A. Ochoa-Perez, Fatigue Performance of a SAE 1045 Steel Coated with a Colmonoy 88 Alloy Deposited by HVOF Thermal Spraying, Surf. Coat. Technol., 2006, 201(5), p 2038-2045

9. J. Cizek, O. Kovarik, J. Siegl, K.A. Khor, and I. Dlouhy, Influence of Plasma and Cold Spray Deposited Ti Layers on HighCycle Fatigue Properties of Ti6Al4V Substrates, Surf. Coat. Technol., 2013, 217, p 23-33

10. A. Ibrahim, R.S. Lima, C.C. Berndt, and B.R. Marple, Fatigue and Mechanical Properties of Nanostructured and Conventional Titania $\left(\mathrm{TiO}_{2}\right)$ Thermal Spray Coatings, Surf. Coat. Technol., 2007, 201(16-17), p 7589-7596
11. O. Kovarik, J. Siegl, and Z. Prochazka, Fatigue Behavior of Bodies with Thermally Sprayed Metallic and Ceramic Deposits, J. Therm. Spray Technol., 2008, 17(4), p 525-532

12. S. Hutařová, K. Obrtlík, M. Juliš, L. Celko, M. Hrčková, and T. Podrábský, Degradation of TBC Coating During Low-Cycle Fatigue Tests at High Temperature, Key Eng. Mater., 2014, 592-593, p 461-464

13. J. Siegl, P. Kantor, and J. Adámek, Fatigue Processes in Bodies with Surface Coatings, Proceedings of the 14th International Conference on Surface Modification Technologies, Paris, France, 2001, vol. 14

14. P. Lukáš and L. Kunz, Cyclic Plasticity and Substructure of Metals, Mater. Sci. Eng. A, 2002, 322(1-2), p 217-227

15. O. Kovarik, J. Siegl, J. Nohava, and P. Chraska, Young's Modulus and Fatigue Behavior of Plasma-Sprayed Alumina Coatings, $J$. Therm. Spray Technol., 2005, 14(2), p 231-238

16. R. Musalek, O. Kovarik, J. Medricky, N. Curry, S. Bjorklund, and P. Nylen, Fatigue Testing of TBC on Structural Steel by Cyclic Bending, J. Therm. Spray Technol., 2014, 24(1), p 168-174

17. I. Jandejsek, O. Jiroušek, and D. Vavř́k, Precise Strain Measurement in Complex Materials Using Digital Volumetric Correlation and Time Lapse Micro-CT Data, Proc. Eng., 2011, 10, p 1730-1735

18. J.D. Carroll, W. Abuzaid, J. Lambros, and H. Sehitoglu, High Resolution Digital Image Correlation Measurements of Strain Accumulation in Fatigue Crack Growth, Int. J. Fatigue, 2013, 57, p $140-150$

19. P. Lorenzino and A. Navarro, The Variation of Resonance Frequency in Fatigue Tests as a Tool for In Situ Identification of Crack Initiation and Propagation, and for the Determination of Cracked Areas, Int. J. Fatigue, 2015, 70, p 374-382

20. J. Poissant and F. Barthelat, A Novel 'Subset Splitting' Procedure for Digital Image Correlation on Discontinuous Displacement Fields, Exp. Mech., 2010, 50(3), p 353-364

21. R. Mušálek, J. Medřický, Z. Pala, O. Kovářík, L. Tomek, N. Curry, S. Bjorklund, and K. Kolařík, Fatigue Performance of TBCs on Hastelloy-X Substrate during Cyclic Bending, Thermal Spray 2015: Proceedings of the International thermal Spray Conference, A. McDonald, A. Agarwal, G. Bolelli, A. Concustell, Y.-C. Lau, F.-L. Toma, E. Turunen, and C. Widener, Ed., May 11-14, 2015 (Long Beach, CA), ASM International, 2015, p 1225

22. M. Cesnik, J. Slavic, and M. Boltezar, Uninterrupted and Accelerated Vibrational Fatigue Testing with Simultaneous Monitoring of the Natural Frequency and Damping, J. Sound Vib., 2012, 331(24), p 5370-5382

23. S. Burger, C. Eberl, A. Siegel, A. Ludwig, and O. Kraft, A Novel High-Throughput Fatigue Testing Method for Metallic Thin Films, Sci. Technol. Adv. Mater., 2011, 12(5), p 054202

24. A. Bovsunovsky and C. Surace, Considerations Regarding Superharmonic Vibrations of a Cracked Beam and the Variation in Damping Caused by the Presence of the Crack, J. Sound Vib., 2005, 288(4-5), p 865-886

25. J. Blaber, B. Adair, and A. Antoniou, Ncorr: Open-Source 2D Digital Image Correlation Matlab Software, Exp. Mech., 2015, 55(6), p 1105-1122

26. H. Guo, S. Kuroda, and H. Murakami, Microstructures and Properties of Plasma-Sprayed Segmented Thermal Barrier Coatings, J. Am. Ceram. Soc., 2006, 89(4), p 1432-1439

27. A. Ibrahim, T. Grund, T. Lampke, D. Wett, D. Nestler, and G. Wagner, TGO formation and failure mode of TBC systems comprising PVD-Al interlayers, Thermal Spray 2015, Proceedings of the International thermal Spray Conference, A. McDonald, A. Agarwal, G. Bolelli, A. Concustell, Y.-C. Lau, F.-L. Toma, E. Turunen, and C. Widener, Ed., May 11-14, 2015 (Long Beach, CA), ASM International, 2015, p 1225

28. K. Slámečka, L. Čelko, P. Skalka, J. Pokluda, K. Němec, M. Juliš, L. Klakurková, and J. Švejcar, Bending Fatigue Failure of Atmospheric-Plasma-Sprayed CoNiCrAlY/YSZ Thermal Barrier Coatings, Int. J. Fatigue, 2015, 70, p 186-195

29. P. Bengtsson and C. Persson, Modelled and Measured Residual Stresses in Plasma Sprayed Thermal Barrier Coatings, Surf. Coat. Technol., 1997, 92(1-2), p 78-86 